\title{
Nitrogen ligands effects in the palladium-catalyzed carbonylation reaction of nitrobenzene to give $N$-methyl phenylcarbamate
}

\author{
Francesco Ferretti, Emma Gallo and Fabio Ragaini*.
}

Università degli Studi di Milano, Dipartimento di Chimica and ISTM-CNR, Via Golgi 19, 20133 Milano, Italy.

*Corresponding author: Phone: (+39)0250314373. Fax: (+39)0250314405. E-mail: fabio.ragaini@unimi.it

\begin{abstract}
We previously reported an enhancement in the catalytic activity of a palladium-phenanthroline system towards the carbonylation of nitroarenes to $N$-methyl arylcarbamates when non-symmetric phenanthrolines were used as ligands. In particular, best results were obtained when an electron donating group was present on just one of the pyridinic rings of the ligand. Here we report the effect of stronger donor groups on the catalytic activity and on the selectivity of the system, even in the presence of different phosphorus acids used as promoters. High catalytic activities were reached but the high basicity of the ligands can negatively affect the product selectivity. The presence of steric hindrance near one or both the nitrogen donor atoms was shown to be detrimental for the activity of the system both with phenanthroline ligands and a quinoline-guanidine hybrid ligand.
\end{abstract}

Keywords: palladium, phenanthroline, $\mathrm{N}$ ligands, reductive carbonylation, isocyanate, nitroarene

\section{Introduction}

Isocyanates are commodity chemicals mostly employed in polyurethane synthesis. Polyurethanes are widely applied in almost every part of modern life in the form of plastic foams, coatings, adhesives, sealants, elastomers and binders [1][2]. The annual world production of isocyanates is several millions metric tons and it is steadily increasing. In particular the most widely employed are aromatic isocyanates, especially toluenediisocyanate (TDI) and 4,4'-methylenediphenylisocyanate (MDI). They account for more than seven million metric tons per year. The industrial interest for these two compounds is evident from the recent investment on new plants by the major producers both in Europe and in Asia. Currently the industrial synthesis of aromatic isocyanates is carried out in two steps from the nitro compounds with very high yields and selectivities. The nitroarene is initially reduced to the corresponding aniline by hydrogenation over a heterogeneous catalyst and subsequently the amine is reacted with phosgene. From an economical point of view, the phosgene-based route seems to be the most effective strategy and the well-established phosgene technology appears to be difficult to replace. However phosgene is very toxic and corrosive, since it is a hydrolysable compound, and it is produced by reaction of carbon monoxide with chlorine that is an energy-intensive material. One of the most developed phosgene-free routes to isocyanate is the palladium- 
catalyzed reductive carbonylation of nitroarenes [3-6]. If this reaction is conducted in the presence of an alcohol, carbamates can be obtained (eq. 1):

$\mathrm{ArNO}_{2}+\mathrm{ROH}+3 \mathrm{CO} \stackrel{\text { cat. }}{\longrightarrow} \mathrm{ArNHCOOR}+2 \mathrm{CO}_{2}$

ArNHCOOR $\stackrel{\Delta \text { or cat. }}{\longrightarrow}$ ArNCO $+\mathrm{ROH}$

Carbamates are important final products and synthetic intermediates for the pharmaceutical [7, 8] and agrochemical industries [9]. In addition they can be thermally [10-13] or catalytically [12] cracked to give isocyanates (eq. 2). Dicarbamates can be directly used in the synthesis of polyurethanes by transcarbamoylation reaction with polyols $[14,15]$. The synthesis of $N$-methyl phenylcarbamate (MPC) in particular was used as a model reaction in many studies on the phosgene-free synthesis of isocyanates. Furthermore MPC itself is an intermediate in the synthesis of 4,4'-diphenylmethane-bis(methyl)carbamate that is a precursor of MDI [16-19].

At the end of the last century, it was found that the most active catalysts for the reductive carbonylation of nitroarenes are those based on palladium and chelating nitrogen ligands [20-27], especially Pd/phenanthroline complexes. Further improvement of the system was obtained using phosphorus acids as bifunctional promoters reaching TON up to $10^{5}$ [28-32]. Mechanistic aspect of the catalytic system were discussed in both two papers [33, 34] and a review [3]. In the mechanism therein proposed the nitroarene is intermediately reduced to the corresponding aniline and only at a later stage carbonylated. This is supported by a zero order kinetic with respect to the nitroarene and a first order kinetic with respect to the amine. The carbonylation step was identified as the rate determining step of the reaction and it is catalyzed by the square-planar complex $\left[\mathrm{Pd}(\mathrm{Phen})\left(\mathrm{COOCH}_{3}\right)_{2}\right]$. The latter, under a carbon monoxide atmosphere, readily forms the species $\left[\mathrm{Pd}(\mathrm{Phen})(\mathrm{CO})\left(\mathrm{COOCH}_{3}\right)_{2}\right]$ that is attacked by a free aniline on the coordinated CO leading to the isocyanate formation. Even if the validity of this mechanism has recently been questioned $[35,36]$, the reasons adduced for criticism are in our opinion too weak with respect to the evidence in its support. Nevertheless there is evidence that several mechanisms can operate in competition with each other with the predominating of one with respect to another depending on the reaction conditions. The mechanistic studies reported by our group is the major under the optimized experimental conditions used in this work.

While studying the mechanism it was noted that the adduct of the catalytic active species with carbon monoxide, $\left[\mathrm{Pd}(\mathrm{Phen})(\mathrm{CO})\left(\mathrm{COOCH}_{3}\right)_{2}\right]$, has a distorted square-planar geometry in which one of the two nitrogen atoms has detached from the metal [33]. The non-symmetric arrangement of the phenanthroline suggested us that hemilable ligands could be more effective than symmetrical ones. We verified this hypothesis in a previous work [37] by testing several mostly new non-symmetric phenanthrolines and both their symmetrical counterparts. In general we noticed that electronically non-symmetric phenanthroline are able to improve the performance of the catalytic system, whereas when a methyl in ortho position is present, it has a severe negative effect on catalyst activity. In particular, donating substituent in the para position of one of the two pyridinic rings and an electron-withdrawing or no substituent on the para position of the other pyridinic ring gave the best increases in activity. An improvement in rate of $19 \%$ with respect to the best value obtainable with 1,10-phenanthroline (Phen) was achieved at 60 bars with 4-methoxyphenanthroline (4-MeOPhen). The spread between the obtained TOF for these two ligands increases with the increase of pressure, (57\% at 100 bar) attaining the highest turnover frequency ever reported for this kind of 
reactions. In the present study we further investigated the influence on the activity of the system of non-symmetric ligands.

\section{Results and discussion}

\subsection{Synthesis of the ligands}

We could previously draw up the absolute order of maximum activity (highest $\mathrm{TOF} / \mathrm{h}^{-1}$ in parentheses): 4methoxyphenanthroline (5710) > 4-carbomethoxy-7-methylphenanthroline (5409) > 4-methylphenanthroline (5326) $>$ 3,4,7,8-tetramethylphenanthroline (5010) > 4,7-dimethylphenanthroline (4911) > 3-ethylphenanthroline $(4810) \approx$ phenanthroline (4803) > 4,7-dimethoxyphenanthroline (4754) > 3-tert-butylphenanthroline (3969) >> 2methylphenanthroline $(571)>$ neocuproine $(\approx 0)($ Chart 1$)$.

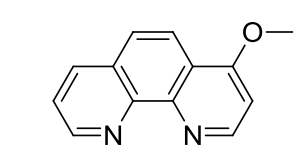

4-MeOPhen (5710)

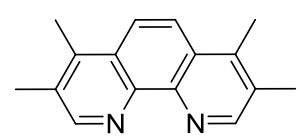

TMPhen (5010)

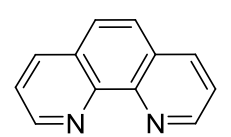

Phen (4803)

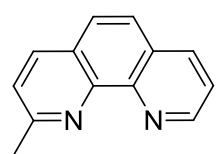

2-MePhen (571)

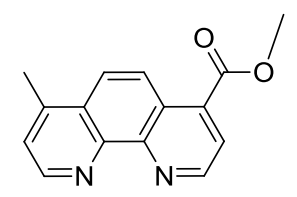

(5409)

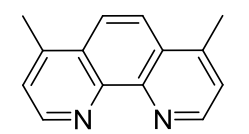

(4911)

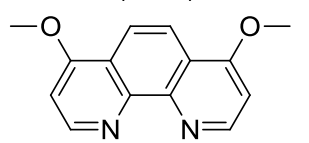

(4754)

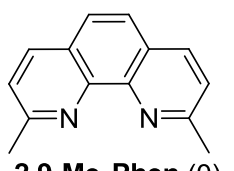

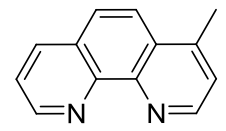

(5326)

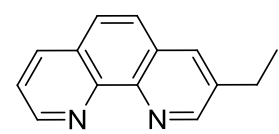

(4810)

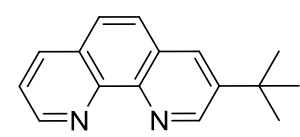

(3969)

Chart 1. Different substituted phenanthrolines tested as ligands in the reductive carbonylation of nitrobenzene in our previous work [37]. Maximum TOF values are reported under the ligands.

Among donor substituents, dialkylamino and arylamino groups were not considered in our previous work due to their high basicity. Indeed, it should be recalled that the acidic promoter plays several roles that are strongly entangled with the basicity of the ligand and of intermediately formed aniline. These effects have been studied in detail [33]. In short:

1) Acids (carboxylic acids, hydroxypyridines, phenanthrolinium salts, phosphorus acids) strongly accelerate the reaction. There is no direct correlation between the pKa of the acid and the activity of the catalytic system, but there is clear evidence that the effect is due to a bifunctional activation and compounds that are better bifunctional catalyst, especially phosphorus acids (diarylphosphinic acids, arylphosphonic acids, phosphoric acid) give by far the best results.

2) The reaction proceeds through the intermediate formation of aniline, which is later carbonylated to phenylisocyanate. The latter is trapped by excess aniline to give diphenylurea, which is finally alcoholyzed 
to methyl phenylcarbamate. The effect of acids on activity is due to the acceleration of a proton transfer in the amine carbonylation step (Scheme 1).

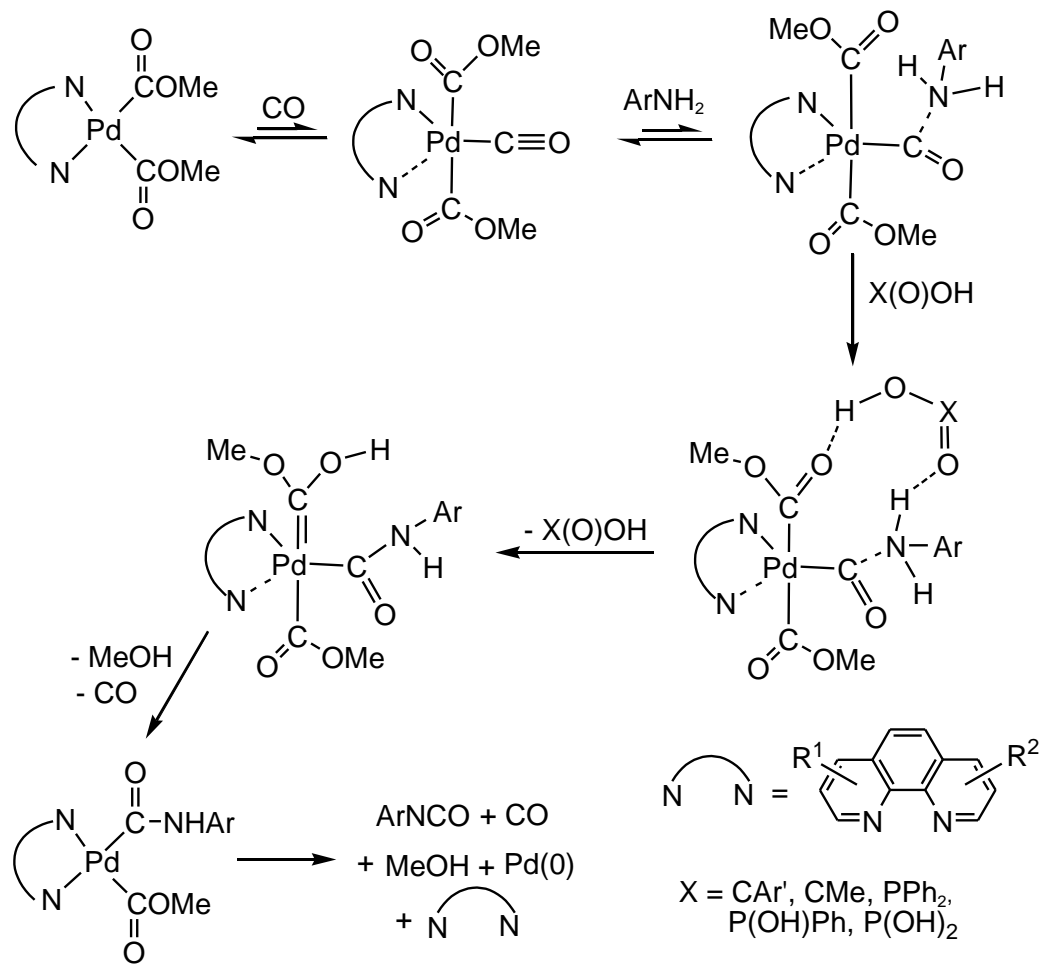

Scheme 1

3) A second role of the acid is to decrease the amount of the byproduct azoxybenzene, whose formation is on the other hand accelerated by the presence of bases [21, 28, 29, 38].

4) The acid is involved in deprotonation equilibria with both the phenanthroline ligand and aniline. These equilibria were studied in detail in the case of diphenylphosphinic acid and unsubstituted phenanthroline and aniline. This was possible because of the lucky event that the $\mathrm{p} K a$ values of phenanthroline and aniline are virtually identical and this allows treating them as just one base. Even so, the study required an extensive series of measurements because the catalytic reactions are run at a temperature, $170{ }^{\circ} \mathrm{C}$, that is outside the range of accessibility of NMR instruments and thermodynamic parameters had to be measured accurately in order to allow a reliable extrapolation. The deprotonation equilibrium constant for the acid under these conditions changed by as much as two orders of magnitude from RT to $170{ }^{\circ} \mathrm{C}$, indicating that using room temperature data to evaluate the actual equilibria under the reaction conditions would be meaningless. The same study would be impossible for either polyprotic acids (arylphosphonic and phosphoric acid) or substituted phenanthrolines, for which the coincidental coincidence of the $\mathrm{p} K a$ value with that of aniline does not hold. Moreover, even the results obtained with diphenylphosphinic acid and phenanthrolines must be considered as approximate, because under the reaction conditions the amount of nitrobenzene and of its reaction products is such to significantly alter the solvent properties.

5) Given what said above, an optimization of the reaction parameters and ligand identity can only be performed on a trial-and-error basis, keeping in mind that a more electronically unbalanced ligand (more strongly donor groups on one pyridinic ring only) should improve the activity of the catalyst, but the 
stronger basicity of the ligand resulting from such a modification will negatively affect the reaction by causing a more extensive acid deprotonation (lower reaction rate) and a more basic environment (higher azoxybenzene selectivity).

As a consequence of what said above, it is not obvious whether the introduction of an amino group on the ligand would result in a further increase in performance of the catalytic system, but the fact that the best result among previously tested ligands was obtained with the most donating among all tested substituents indicates that this would surely worth trying. The choice of the substituent was made considering the Hammett constants $(\sigma)$ of various amine fragments [39, 40]. Piperidyl- and anilino- fragments were considered suitable for the synthesis of the phenanthroline ligands because of their $\sigma$ values (respectively -0.41 and -0.56 ), intermediate between the lesser donating methoxy group $(\sigma=-0.27)$ and the highly donating dimethyl amino group $(\sigma=-0.83)$. In our previous work 3,4-dimethylphenanthroline (3,4-DMPhen) was not tested while we tried in catalysis the commercially available symmetrical 3,4,7,8-tetramethylphenanthroline (TMPhen). Here we conclude the comparison among the methyl substituted phenanthrolines series. In addition, the almost complete inhibition of the catalytic activity exerted by $o$-methyl groups was quite surprising. To verify if it could be caused by a cyclopalladation reaction of the methyl, we tested the symmetrical 2,9-dimethoxyphenanthroline (2,9-(MeO) $\left.{ }_{2} \mathrm{Phen}\right)$ and non-symmetrical 2methoxyphenanthroline (2-MeOPhen). Indeed the methoxy group is known to be less prone to metalation. The last non-symmetric ligand that was tested is a guanidine-quinoline hybrid ligand: $N$-(1,3-dimethylimidazolidin-2ylidene)quinolin-8-amine (DMEGqu). Guanidines are among the strongest neutral organic bases due to their ability to stabilize positive charges [41, 42]. The hybrid ligands guanidine-quinoline combines the excellent donor properties of guanidines while leaving the possibility to the pyridinic nitrogen atom to detach.

The dipyrido[3,2-a:2',3'-c]phenazine (DPPZ) and 2-phenylimidazo[4,5-f][1,10]phenanthroline (PIPhen) ligands were also considered in this study because they have low energy $\pi^{*}$ orbitals, due to their extended aromatic systems. This make them better acceptors than phenanthroline moiety itself and could stabilize the metal $\mathrm{d}_{\pi}$ orbital by $\mathrm{d}_{\pi}-\pi^{*}$ back bonding interactions while maintaining the $\sigma$ donor capability and rigidity of phenanthrolines.

All the ligands employed were not commercially available and they were prepared according to literature procedures or adapting and combining previously reported reactions. The synthetic strategies employed are shown in Schemes 2-7.

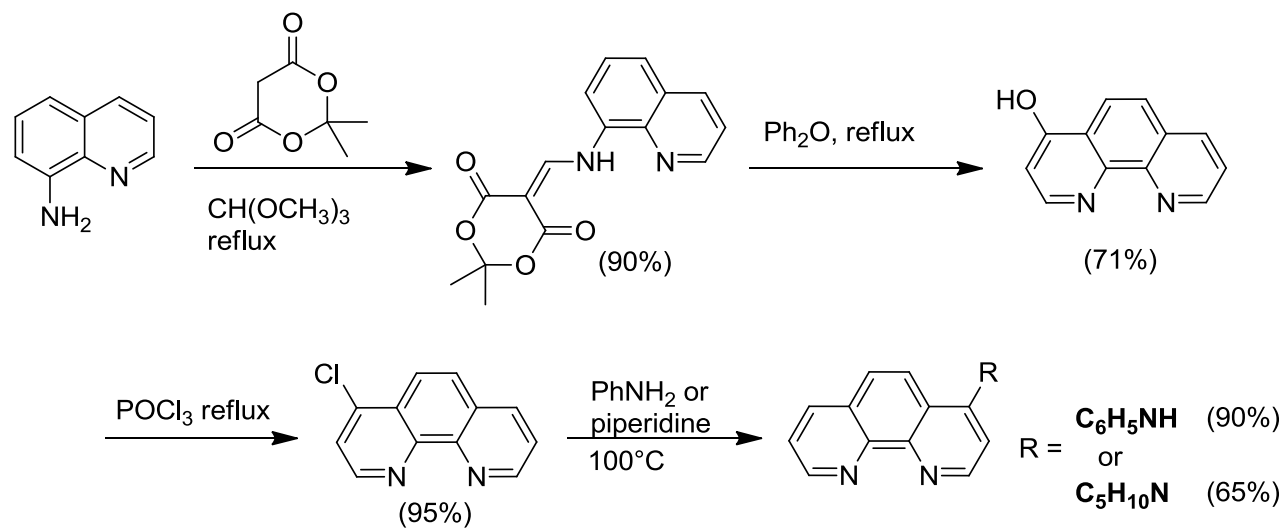

Scheme 2 


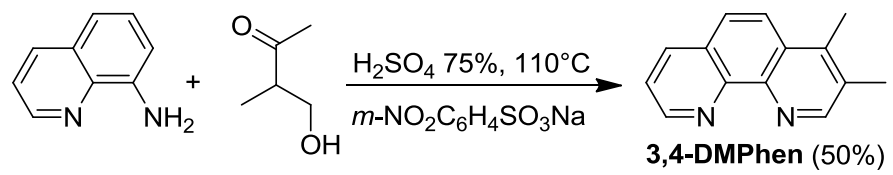

Scheme 3

The syntheses of the two amino substituted phenanthrolines [43] and 3,4-DMPhen [44] were previously reported in the literature. However here we report different, more efficient, syntheses (Schemes 2-3) and a complete characterization that was lacking.

Phenanthrolines bearing an amino group were prepared by a nucleophilic substitution of chloride on 4chlorophenanthroline. Although Katritzky and coworkers stated that severe conditions cause extensive decomposition and mild conditions result in no chloride displacement [43], we performed the reaction under a nitrogen atmosphere at $100{ }^{\circ} \mathrm{C}$ obtaining a quite pure product. 4-Chlorophenanthroline itself was prepared as previously reported by our group [37].

3,4-DMPhen was synthesized from 8-aminoquinoline and 4-hydroxy-3-methyl-2-butanone employing a modified Skraup reaction. The reaction was performed in $75 \% \mathrm{H}_{2} \mathrm{SO}_{4}$ employing a stoichiometric amount of sodium 3-nitrobenzenesulfonate as the oxidant (Scheme 3). The use of this salt is known to afford better yields and a more pure product than other oxidizing agents [45].

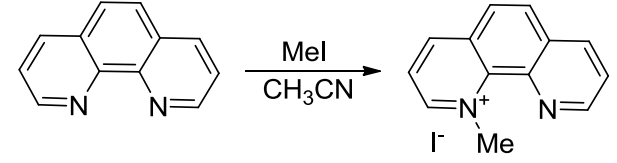

(91\%)

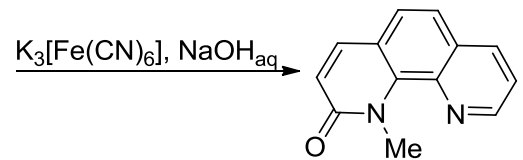

(90\%)

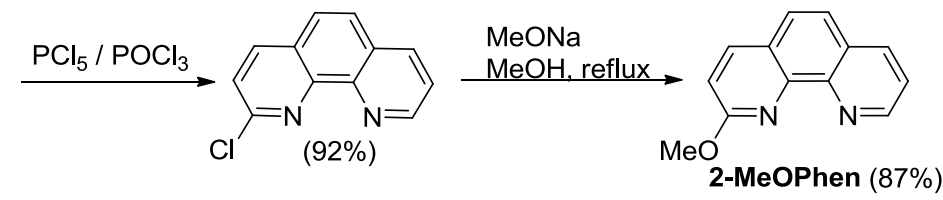

Scheme 4

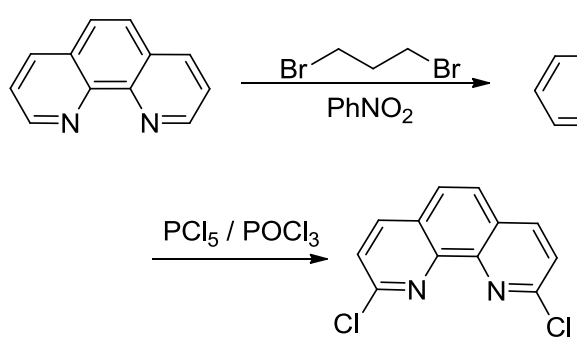

$(83 \%)$

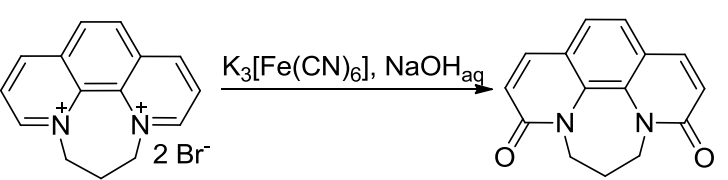

(27\%)

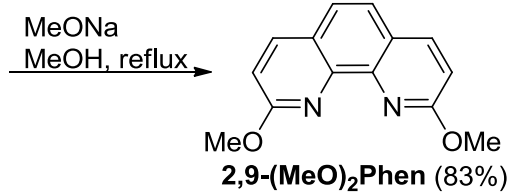

Scheme 5

The two ortho methoxy substituted phenanthrolines were synthesized as previously reported in the literature from the corresponding chloro substituted compounds [46]. 2-MeOPhen was prepared by methylation of one nitrogen of 1,10-phenantroline with MeI, oxidation with $\mathrm{K}_{3}\left[\mathrm{Fe}(\mathrm{CN})_{6}\right]$ to 1-methyl-1,10-phenanthroline-2-one followed by chlorination of the ketone with a mixture of $\mathrm{POCl}_{3} / \mathrm{PCl}_{5}$ and nucleophilic substitution of chloride by sodium methylate (Scheme 4). With an analogous procedure 2,9-(MeO $)_{2}$ Phen was synthesized from the N,N'-propanebridged bis(quaternary salt) of 1,10-phenanthroline (Scheme 5). 


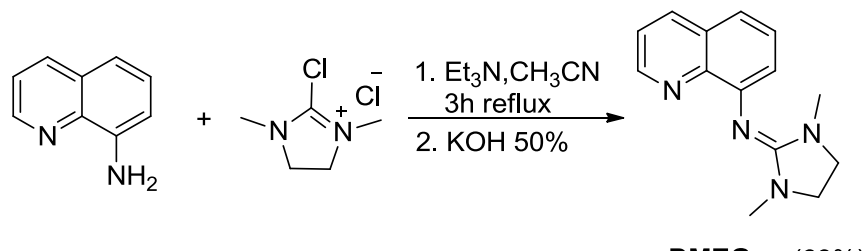

DMEGqu (69\%)

\section{Scheme 6}

The guanidine-quinoline hybrid ligand, DMEGqu, was synthesized by condensation of 8 -aminoquinoline with N,N'-dimethylethylenechloroformamidinium chloride as previously reported (Scheme 6) [41]. The chloroformamidiunium salt itself was prepared by the reaction of 1,3-dimethyl-2-imidazolidinone with oxalyl chloride [47], instead of employing the highly toxic phosgene as reported in previously published accounts.

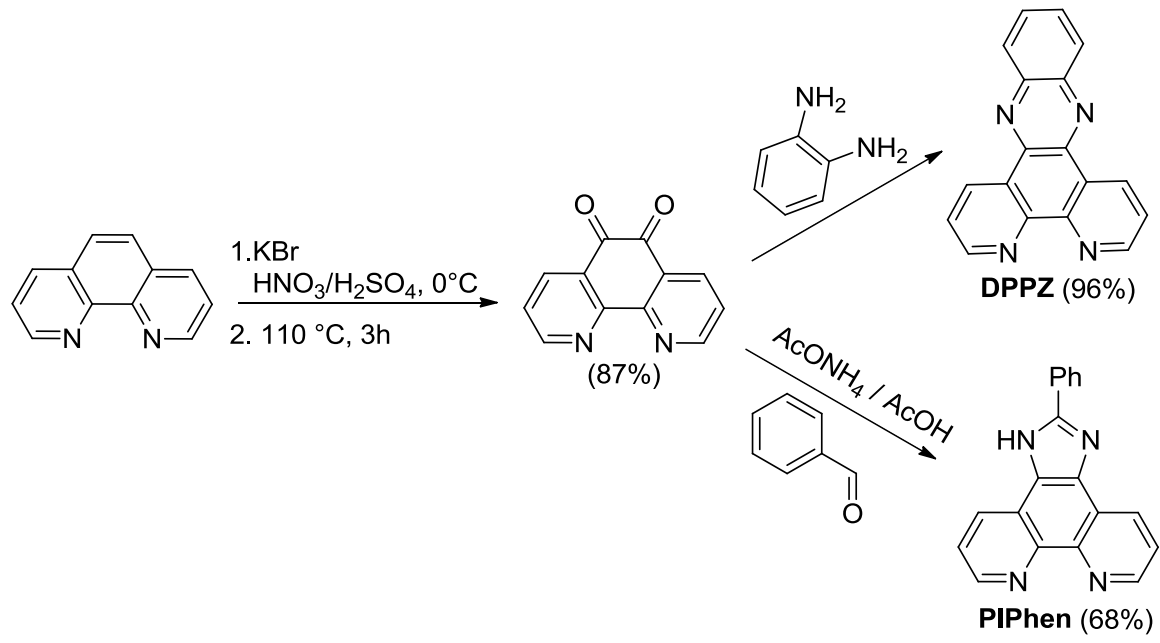

\section{Scheme 7}

DPPZ and PIPhen were both synthesized starting from 1,10-phenanthrolin-5,6-dione (Scheme 7). The last compound was previously reported to be easily obtainable from 1,10-phenanthroline oxidation by sulfo-nitric mixture and an excess of $\mathrm{KBr}$. However the most recent procedures are imprecise and a large amount of a noncompletely oxidized byproduct containing bromine was obtained. A more detailed synthetic method was reported by Yamada [48], which suggest more careful addition of reagents to avoid side-products formation. The dione is then reacted with 1,2-phenylenediamine in methanol to yield DPPZ or with ammonium acetate and benzaldehyde in acetic acid to yield PIPhen.

\subsection{Comparison of catalytic activities}

The reaction of carbonylation of nitroarenes to carbamates is generally conducted at relatively high pressures and temperatures. Under these conditions it is known that the detachment of the nitrogen chelating ligands from the metal center is very easy. To ensure a fast re-coordination to the catalyst and avoid decomposition, an excess free ligand should be used. In the catalytic system employed in this study the best molar excess varies widely (from a few mol\% to more than 500 fold) with the experimental conditions but in particular with the identity of the ligand [37]. To have a reliable comparison, different ligand/metal ratio were employed, individual ligand ratio/activity curves for each ligand were determined and their maxima compared.

A series of carbonylation reactions of nitrobenzene have been performed employing methanol as the solvent, yielding MPC as the main product. All catalytic tests have been performed employing the same reaction conditions 
reported in our previous work [37] to allow a comparison among the new data and the old ones. A very high catalytic ratio of 15200 (or $6.58 \times 10^{-3} \mathrm{~mol} \%$ ) was used in order to avoid approaching complete conversion even with the most active systems. Except for the ligand identity and ligand/palladium ratio, all the other reaction parameters were kept constant. Temperature $\left(170{ }^{\circ} \mathrm{C}\right)$, identity of the acidic promoter $\left(\mathrm{H}_{3} \mathrm{PO}_{4} 85 \%\right)$ and the concentration of the reagents, except for the ligand and the catalyst, are those previously optimized for 1,10phenanthroline [29]. A small amount of initially added aniline (ca. 2.6 mol \% with respect to nitrobenzene) was employed to avoid induction time of the reaction [28, 29, 33]. Dimethoxypropane was also added as an internal drying agent, as its positive effect on the selectivity was previously reported [29, 49]. The employed carbon monoxide pressure was fixed at 60 bars for technical reasons even though better results could be obtained at higher pressures $[28,29,37]$. As in our previous study, $\left[\mathrm{Pd}(\mathrm{Phen})_{2}\right]\left[\mathrm{BF}_{4}\right]_{2}$ was employed as the catalyst [50]. Results are reported in Table S1 together with the data relative to the unsubstituted phenanthroline, the best performing 4MeOPhen, TMPhen, 2-methylphenanthroline (2-MePhen) and 2,9-dimethylphenanthroline (2,9-Me ${ }_{2}$ Phen), reported as a comparison. A graphical representation of ligand ratio/activity curves is reported in Figure 1 . The activity of the system is represented by the turnover frequency (TOF) values calculated over all the reaction time for nitrobenzene conversion. These are a good index of the reaction rate since the kinetics is zero-order in nitrobenzene. It should be noted from the results reported in Table S1 that the mass balance of the phenyl containing compounds is not complete. This is mainly caused by the formation of diphenylurea, which cannot be detected by gas chromatography. It is intermediately formed and alcoholyzed to MPC and aniline during the reaction [33]. For short reaction times, the alcoholysis is incomplete, thus the carbamate selectivity values could be misleading as an indicators of the actual selectivity of the reaction. The main side products that do not reenter the cycle or evolve to carbamate in short times, are azo-, azoxybenzene and methyl $\mathrm{N}$-( $p$-methoxy)phenylcarbamate. Thus the amount of these compounds is the only indirect quantitative measure of the selectivity of the reaction. 


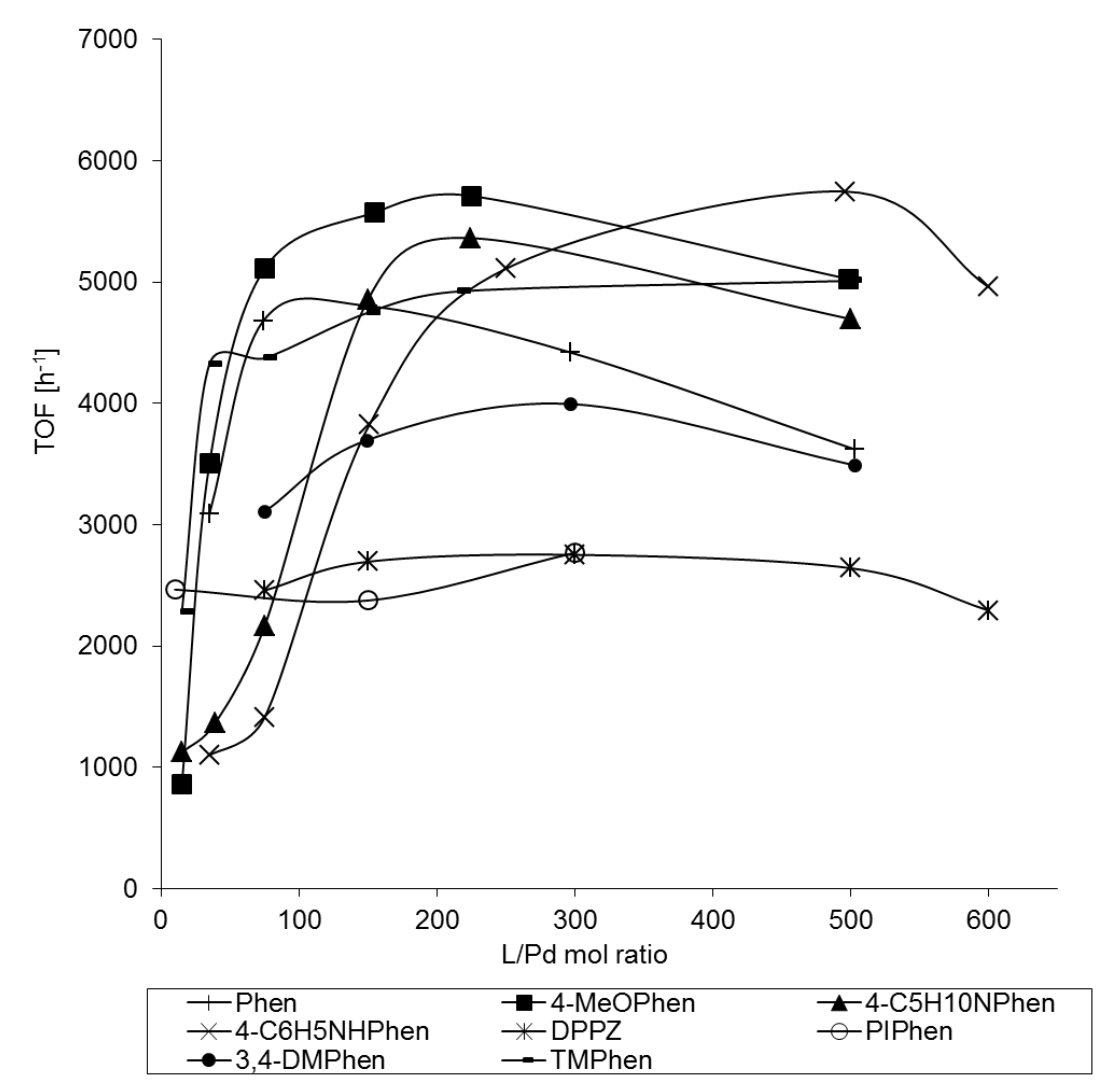

Figure 1. Graphical representation of catalyst activity for catalytic tests using different phenanthrolines as ligands. Data from Table S1.

In our previous work we reported that, in most cases, the activity of the system shows a sharp increase with the increase in ligand concentration up to an optimal value, followed by a much slower decrease when this value is exceeded [37]. The curves of the two amino substituted phenanthroline showed an initially more gradual increase of activity instead. This behavior recalls the ligand ratio/activity curves obtained for 4,7-dimethoxyphenanthroline and TMPhen, in which a small plateau was present at intermediate ligand/Pd ratios, followed by a further rate increase. The different pattern is ascribable to the higher basicity of these ligands that can be partially protonated by phosphoric acid, present as a promoter, altering all the equilibria in the system.

The maxima of activity obtained using the two amino ligands were higher than that obtained with Phen and in the case of 4-anilinophenanthroline the maximum is even slightly higher than that of 4-MeOPhen. There is apparently no direct correlation between the activity and the donor capability of the substituent since protonation equilibria are involved. The acid-base equilibria between the ligands and the acidic promoter are difficult to rationalize since the reaction is conducted in the presence of not negligible amount of the aprotic nitrobenzene that is less polar then methanol. This could affect the basicity of the ligands and their effect on the catalytic reaction. Nevertheless among the two amino substituted ligands the less basic ligand, 4-piperidinylphenanthroline, gave a lower maximum of activity. The main drawback in the use of these highly basic ligands is the increase in azoxybenzene selectivity, as may be expected based on the general trends discussed above.

3,4-DMPhen gave only poor result with respect to phenanthroline. This was not expected since the symmetric TMPhen gave a maximum of activity higher than phenanthroline itself. From the previous work we noticed that the 
presence of an alkyl group in meta position had a limited positive effect, probably due to steric hindrance. Indeed the reaction mechanism requires the formation and interaction with aniline and acid co-catalyst of the highly crowded distorted square planar adduct of bis-alkoxycarbonyl complex with CO. Thus even a low steric hindrance could be detrimental and overcome the beneficial electronic effect. This is not evident for TMPhen because the electronic effect is stronger.

DPPZ and PIPhen gave much lower activity maxima with respect to that obtained with phenanthroline. This result is a bit surprising since no negative effect should arise from an extended $\pi$ system, thus an activity at least similar to that of phenanthroline was expected. However in DPPZ the extended planar $\pi$-system enhance the $\pi$ stacking interactions among the ligands reducing their solubility even when non-coordinated [51]. This phenomenon is less marked for PIPhen, that is more soluble in the free form, though the imidazole ring act as an hydrogen bond donor/acceptor enhancing the number of interactions among molecules [52, 53]. The formation of supramolecular aggregates could explain a reduced reactivity of the complexes.

The strong inhibiting effect exerted by ortho-methyl groups on the phenanthroline ligand, was present also when ortho-methoxy substituents are employed. At all concentrations, the catalytic tests showed an almost complete deactivation of the system permitting us to conclude that the negative effect is likely of steric nature. A likely explanation is that the presence of ortho substituents on the ligands hinders the approach of the nitroarene to the metal center and its reduction to aniline. This prevents the reduction of the $\mathrm{Pd}^{\mathrm{II}}$ complexes leading to the accumulation of $\mathrm{Pd}^{0}$ species and then to Pd black formation. To prove that only the reduction of nitrobenzene and not the carbonylation step is hindered, we performed a stoichiometric reaction between the complex $[\operatorname{Pd}(2,9$ $\left.\left.\mathrm{Me}_{2} \mathrm{Phen}\right)(\mathrm{COOMe})_{2}\right]$ and $p$-toluidine under a $\mathrm{CO}$ atmosphere in the presence of benzoic acid as a cocatalyst, as previously reported for the complex $\left[\mathrm{Pd}(\mathrm{Phen})(\mathrm{COOMe})_{2}\right]($ Scheme 1 , with $\mathrm{Ar}=p$-tol, $\mathrm{X}=\mathrm{CPh}, \mathrm{N}-\mathrm{N}=2,9$ $\mathrm{Me}_{2}$ Phen) [33]. The reaction takes place even at $0^{\circ} \mathrm{C}$ yielding tolylisocyanate that, in the presence of excess toluidine, gives the corresponding urea. Toludine instead of aniline was employed to allow a better identification of the product by ${ }^{1} \mathrm{H}$ NMR. The easy reaction of the sterically hindered palladium(II) intermediate with amines strongly supports the view that steric hindrance is a problem at an earlier stage of the catalytic cycle.

The same explanation applies to DMEGqu in which the guanidine fragment is even more sterically hindered than methyl- and methoxy-substituted phenanthrolines (for clarity the curve relative to 2-MeOPhen, 2,9$(\mathrm{MeO})_{2}$ Phen and DMEGqu were not reported in Figure 1).

\subsection{Influence of phosphorus acids promoters}

The catalytic results discussed above were obtained using phosphoric acid as cocatalyst. Although the presence of this promoter is not necessary, when it is used the rate of the carbonylation step of the reaction is enhanced resulting in very high TOF and TON.

From previous studies in our [25, 28, 29, 31] and other research groups [38, 54] on the effect of different acids as cocatalysts, it is evident that the efficiency of the promoter is not directly correlated to the $\mathrm{p} K a$ of the acid and that phosphorus acids are far better than carboxylic acids. Among the phosphorus acids previously tested [28-30], it emerged that, besides $85 \% \mathrm{H}_{3} \mathrm{PO}_{4}$, diphenylphosphinic acid and phenylphosphonic acid were very effective in promoting the catalytic reaction. They gave slightly lower activities than $85 \% \mathrm{H}_{3} \mathrm{PO}_{4}$, but the selectivities in carbamates were higher. Catalytic tests were performed changing the promoter identity and in some cases their 
concentration. The two amino substituted phenanthrolines were employed as ligands as well as 4-MeOPhen and Phen. Selected catalytic results relative to the maxima of activity are reported in Table 1 (complete data are reported in Table S2). In all cases, when the two organic acids were employed, the maxima of catalytic activity were found to be lower with respect to that obtained with the same ligand in the presence of $\mathrm{H}_{3} \mathrm{PO}_{4}$. However the selectivities in azoxybenzene decreased while the selectivity in MPC increased in most cases. Azoxybenzene formation is reduced by about $30 \%$ also when $\mathrm{PhP}(\mathrm{O})(\mathrm{OH})_{2}$ is employed together with the two amino ligands and is almost halved when $\mathrm{Ph}_{2} \mathrm{P}(\mathrm{O}) \mathrm{OH}$ is the promoter. 4-MeOPhen gave the best results with both organic phosphorus acids with respect to the other ligands employed with the same acids and even when compared with the best performance obtained by using Phen and $\mathrm{H}_{3} \mathrm{PO}_{4}$. Even if the maxima obtained with the two amino substituted are lower than that obtained with $\mathrm{Phen} / \mathrm{H}_{3} \mathrm{PO}_{4}$ system, it should be noted that the optimal amount of acidic promoter varies both with promoter and ligand identity, thus the molar ratio employed in this study could be far from the optimal value.

Table 1. Selected data for nitrobenzene carbonylation reactions catalyzed by $\left[\mathrm{Pd}(\mathrm{Phen})_{2}\right]\left[\mathrm{BF}_{4}\right]_{2}$ and differently substituted phenanthrolines, in the presence of different acidic promoters. Full data in Tables S1 and S2 ${ }^{a}$

\begin{tabular}{|c|c|c|c|c|c|c|c|}
\hline Entry & Ligand & $\begin{array}{c}\mathrm{L} / \mathrm{Pd} \\
\mathrm{mol} \\
\text { ratio }\end{array}$ & $\begin{array}{l}\text { Acidic } \\
\text { promoter }\end{array}$ & $\begin{array}{c}\mathrm{PhNO}_{2} \\
\text { conv.[\%] }\end{array}$ & $\begin{array}{c}\text { MPC } \\
\text { sel.[\%] }\end{array}$ & $\begin{array}{c}\mathrm{PhN}(\mathrm{O}) \mathrm{NPh} \\
\text { sel.[\%] }\end{array}$ & $\mathrm{TOF}\left[\mathrm{h}^{-1}\right]^{d}$ \\
\hline 1 & Phen & 150 & $\mathrm{H}_{3} \mathrm{PO}_{4}$ & 47.6 & 74.9 & 2.9 & 4803 \\
\hline 2 & Phen & 150 & $\mathrm{Ph}_{2} \mathrm{P}(\mathrm{O}) \mathrm{OH}$ & 33.9 & 83.1 & 2.6 & 3444 \\
\hline 3 & Phen & 75 & $\mathrm{PhP}(\mathrm{O})(\mathrm{OH})_{2}$ & 43.2 & 75.0 & 2.5 & 4363 \\
\hline 4 & 4-MeOPhen & 225 & $\mathrm{H}_{3} \mathrm{PO}_{4}$ & 56.1 & 71.1 & 5.8 & 5710 \\
\hline 5 & 4-MeOPhen & 150 & $\mathrm{Ph}_{2} \mathrm{P}(\mathrm{O}) \mathrm{OH}$ & 49.0 & 87.5 & 3.4 & 4982 \\
\hline 6 & 4-MeOPhen & 300 & $\mathrm{PhP}(\mathrm{O})(\mathrm{OH})_{2}$ & 50.1 & 72.9 & 3.9 & 5060 \\
\hline 7 & 4- $\mathrm{C}_{5} \mathrm{H}_{10} \mathrm{NPhen}$ & 225 & $\mathrm{H}_{3} \mathrm{PO}_{4}$ & 52.7 & 66.7 & 9.3 & 5363 \\
\hline 8 & 4- $\mathrm{C}_{5} \mathrm{H}_{10} \mathrm{NPhen}$ & 500 & $\mathrm{H}_{3} \mathrm{PO}_{4}{ }^{e}$ & 51.4 & 52.6 & 17.7 & 5229 \\
\hline 9 & 4- $\mathrm{C}_{5} \mathrm{H}_{10} \mathrm{NPhen}$ & 150 & $\mathrm{Ph}_{2} \mathrm{P}(\mathrm{O}) \mathrm{OH}$ & 38.7 & 75.4 & 4.7 & 3939 \\
\hline 10 & 4- $\mathrm{C}_{5} \mathrm{H}_{10} \mathrm{NPhen}$ & 225 & $\mathrm{PhP}(\mathrm{O})(\mathrm{OH})_{2}$ & 40.3 & 66.2 & 6.1 & 4071 \\
\hline 11 & 4- $\mathrm{C}_{6} \mathrm{H}_{5} \mathrm{NHPhen}$ & 500 & $\mathrm{H}_{3} \mathrm{PO}_{4}$ & 56.5 & 70.7 & 12.1 & 5746 \\
\hline 12 & 4- $\mathrm{C}_{6} \mathrm{H}_{5} \mathrm{NHPhen}$ & 500 & $\mathrm{H}_{3} \mathrm{PO}_{4}{ }^{e}$ & 59.1 & 54.4 & 17.4 & 6013 \\
\hline 13 & 4- $\mathrm{C}_{6} \mathrm{H}_{5} \mathrm{NHPhen}$ & 250 & $\mathrm{Ph}_{2} \mathrm{P}(\mathrm{O}) \mathrm{OH}$ & 43.5 & 64.6 & 5.0 & 4394 \\
\hline 14 & 4- $\mathrm{C}_{6} \mathrm{H}_{5} \mathrm{NHPhen}$ & 500 & $\mathrm{PhP}(\mathrm{O})(\mathrm{OH})_{2}$ & 44.2 & 73.5 & 7.4 & 4460 \\
\hline
\end{tabular}

${ }^{a}$ Experimental conditions: molar ratios $\mathrm{PhNO}_{2} / \mathrm{PhNH}_{2} / \mathrm{Acid} /\left[\mathrm{Pd}(\mathrm{Phen})_{2}\right]\left[\mathrm{BF}_{4}\right]_{2}=15200: 400: 1400: 1,\left[\mathrm{Pd}(\mathrm{Phen})_{2}\right]\left[\mathrm{BF}_{4}\right]_{2}=7.1 \times$ $10^{-5} \mathrm{mmol}$, in $\mathrm{MeOH}(1 \mathrm{~mL})+2,2$-dimethoxypropane $(34 \mu \mathrm{L}), \mathrm{P}_{\mathrm{CO}}=60$ bar, at $170{ }^{\circ} \mathrm{C}$ for $1.5 \mathrm{~h} . \mathrm{PhNH}_{2}$, azo-, azoxybenzene and methyl N-(p-methoxyphenyl)carbamate were also found at the end of the reaction (see the Supporting Information for complete data). ${ }^{b}$ Calculated with respect to the initial $\mathrm{PhNO}_{2}$ amount. ${ }^{c}$ Calculated with respect to the sum of the reacted $\mathrm{PhNO}_{2}$ and $\mathrm{PhNH}_{2}$ amounts. ${ }^{d} \mathrm{TOF}=$ turnover frequency $=\mathrm{mol} \mathrm{PhNO}_{2}$ reacted $/(\mathrm{mol} \mathrm{Pd} \times \mathrm{h}) .{ }^{e}$ The amount of the acid promoter was doubled, molar ratio Acid/[Pd(Phen $\left.)_{2}\right]\left[\mathrm{BF}_{4}\right]_{2}=2800: 1$ 


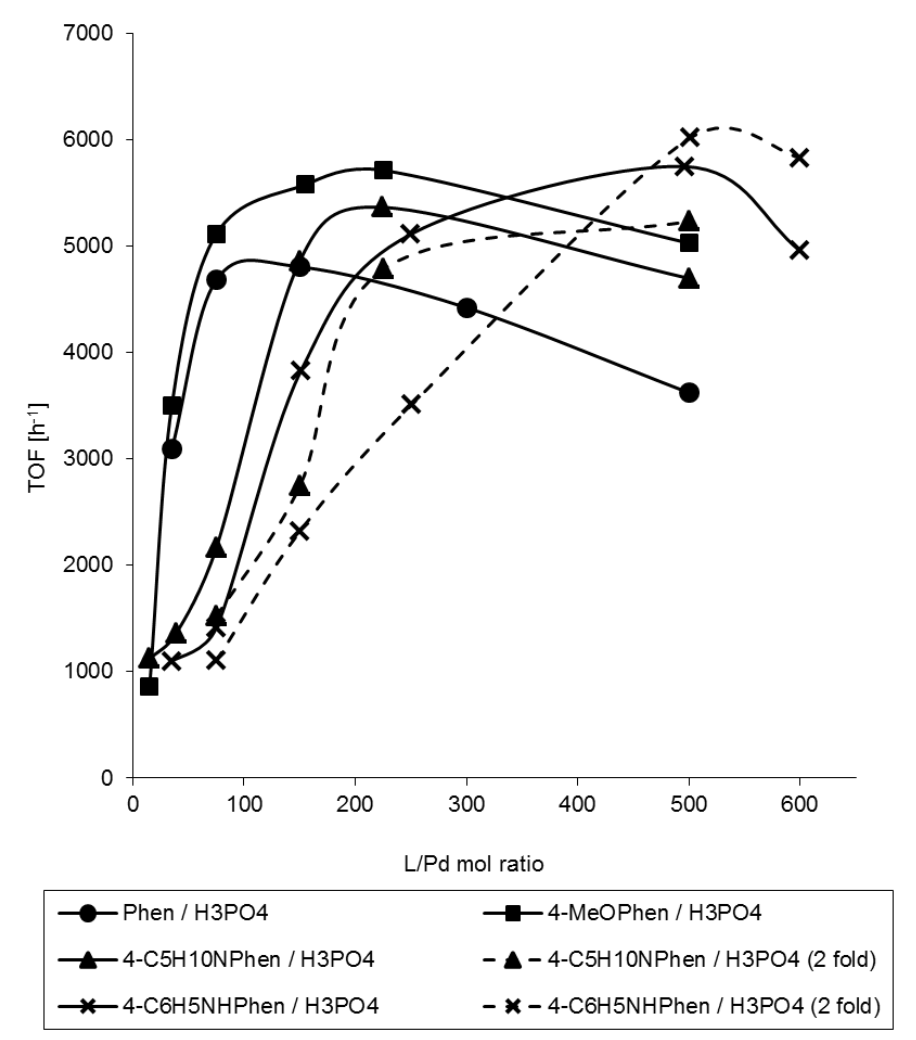

Figure 2. Graphical representation of catalyst activity for catalytic tests using different phenanthrolines at different $\mathrm{H}_{3} \mathrm{PO}_{4}$ concentration. Data from Table $\mathrm{S} 2$.

An opposite behavior was found when the amount of phosphoric acid was increased two fold with respect to the standard conditions (Figure 2). Employing the two amino phenanthrolines, the maximum activity of the system is slightly enhanced while there is a significant increase in azoxybenzene selectivity and concomitant decrease of MPC selectivity. The maximum of anilinophenanthroline is the highest ever obtained at this pressure, but selectivity in azoxybenzene is high (17.4\%). However since $85 \% \mathrm{H}_{3} \mathrm{PO}_{4}$ was employed, also the amount of water was increased, leading to higher azoxybenzene selectivities. It is possible that a fine optimization of the amount of dehydrating agent at every $\mathrm{H}_{3} \mathrm{PO}_{4}$ concentration and the optimization of the organic phosphorus acids concentrations could lead to better results, though this was out of the scope of this study. From the results is evident that the acidity of the promoter influences widely the protonation equilibria in solution when highly basic phenanthrolines are employed. The influence is marked on the azoxybenzene selectivity on which a positive effect could be detected when the acidity of the promoter is lower. The onset of protonation equilibria is also evident in the fact that when a double amount of acid is employed, the maximum of activity as a function of ligand amount is found at a higher ligand/Pd ratio.

\section{Conclusions}

On the basis of previously obtained results, different non-symmetric ligands were tested. Good results were obtained even with the highly basic amino-substituted phenanthrolines. With 4-anilinophenanthroline, the record activity for the carbonylation of nitrobenzene with any catalytic system at 60 bar CO pressure was obtained. Note 
that activities are higher at higher pressures, but the activity order is usually not altered. So this ligand is likely to be that leading to highest activities under any condition. The nature of the amino fragment strongly influences the ligand performance. Byproducts formation is enhanced by the basicity of the ligand due to the extensive deprotonation of the acidic promoter. A positive effect was noted when a less acidic promoter was employed allowing to obtain very high MPC selectivities, although with a little activity decrease. Both with phenanthrolines and DMEGqu it was noted that substituents near to the donor nitrogen atoms deactivate the catalytic system almost completely letting us conclude that steric hindrance around the metal center prevents the substrate approach and thus the progress of the reaction.

\section{Experimental section}

\subsection{Materials and general procedures}

All manipulations of the reagents involved in the catalytic reactions were conducted under a dinitrogen atmosphere. All solvents used in the catalytic reactions were dried by standard procedures and distilled under dinitrogen immediately before use. All glassware and magnetic stirring bars used in catalytic reactions were kept in an oven at $120^{\circ} \mathrm{C}$ for at least two hours and allowed to cool under vacuum before use. 1,10-Phenanthroline (Phen) was purchased as hydrate and dried over $\mathrm{Na}_{2} \mathrm{SO}_{4}$ in $\mathrm{CH}_{2} \mathrm{Cl}_{2}$. After evaporating in vacuo the filtered solution, it was then stored under dinitrogen to avoid water uptake. The same procedure was applied to all the synthesized ligands employed in catalytic reactions. Nitrobenzene and aniline were distilled and stored under dinitrogen before use. Triethylamine was distilled over $\mathrm{CaH}_{2}$ and kept under a dinitrogen atmosphere. 4-Chlorophenanthroline [37], 4hydroxy-3-methyl-2-butanone [55], $\left[\mathrm{Pd}(\mathrm{Phen})_{2}\right]\left[\mathrm{BF}_{4}\right]_{2}$ [24] and $\left[\mathrm{Pd}\left(2,9-\mathrm{Me}_{2} \mathrm{Phen}\right)(\mathrm{COOMe})_{2}\right]$ [33, 56] were prepared and characterized according to the procedures reported in the literature. All other chemicals were purchased from Aldrich or Alfa Aesar. NMR spectra were recorded on a on a Bruker Avance 300-DRX, or on a Bruker Avance 400-DRX spectrometers. Elemental analyses were recorded on a PerkinElmer $2400 \mathrm{CHN}$ elemental analyzer.

\subsection{Catalytic reactions}

For a typical catalytic reaction, stock solutions of the catalyst, $\mathrm{PhNH}_{2}$, and $\mathrm{DMOP}$ (2,2-dimethoxypropane) in nitrobenzene and of the ligand and $\mathrm{H}_{3} \mathrm{PO}_{4}$ (85\% in water) in methanol were prepared under dinitrogen, and the reagent amounts measured by volume to avoid errors in weighing very small amounts of materials. Reagent amounts are reported in the tables or in their footnotes, but in all cases the catalyst concentration was $6.20 \times 10^{-2}$ $\mathrm{mM}$ and $\left[\mathrm{PhNO}_{2}\right]=0.942 \mathrm{M}$ (all reagent volumes are included in the concentration calculation, as they are not negligible). The reactions were conducted in parallel in three $10 \mathrm{~mm}$ wide $\times 40 \mathrm{~mm}$ high test tubes, each having a magnetic stirring bar, which were located in the holes of an aluminum block designed to fit a $200 \mathrm{~mL}$ stainless steel autoclave. The block and the test tubes were placed inside a Schlenk tube with a wide mouth and the reagents added under dinitrogen. Each tube was closed with a screw cap with a glass wool-filled open mouth that allows gaseous reagents to exchange, and the block was rapidly transferred to the autoclave. The autoclave was purged from air, charging $\mathrm{CO}$ at 60 bar and discharging to 2 bar one time before performing the reaction. $\mathrm{CO}$ was then charged at room temperature at $60 \mathrm{bar}$, and the autoclave was immersed in an oil bath preheated at $170{ }^{\circ} \mathrm{C}$. Other experimental conditions are reported in the captions to the tables. At the end of the reaction the autoclave was quickly cooled with 
an ice bath and vented, and the products were analyzed by gas chromatography (Dani 8620 gas chromatograph, equipped with a Supelco SLB-5 ms column (L $30 \mathrm{~m} \times$ I.D. $0.25 \mathrm{~mm}, \mathrm{~d}_{\mathrm{f}} 0.25 \mu \mathrm{m}$ ); naphthalene was used as an internal standard; $\mathrm{CH}_{2} \mathrm{Cl}_{2}, 1 \mathrm{~mL}$, was added to the solution before taking a sample for the $\mathrm{GC}$ analysis to allow complete dissolution of naphthalene.

\subsection{Ligand syntheses}

The detailed procedures for the synthesis and the characterization of 4-aminophenanthrolines and 3,4dimethylphenanthroline are reported below. The syntheses and characterizations of the other ligands and intermediate compounds where previously reported in the literature. Some of them have been synthesized by procedures modified with respect to those previously published. Full details are reported in the supporting material.

\section{4-Aminophenanthrolines. General procedure}

A Schlenk flask was charged with 4-chlorophenanthroline $(450 \mathrm{mg}, 2.10 \mathrm{mmol})$ and the amine (42 mmol) under a dinitrogen atmosphere. The mixture was heated at $100{ }^{\circ} \mathrm{C}$ under magnetic stirring for $6 \mathrm{~h}$ and then allowed to cool. At room temperature the mixture is solid or semi-solid depending on the amine due to the formation of the product and quaternary ammonium salts. The mixture was suspended in $1 \mathrm{M} \mathrm{NaOH}(40 \mathrm{~mL})$ and extracted with $\mathrm{CH}_{2} \mathrm{Cl}_{2}(3 \times$ $40 \mathrm{~mL}$ ). The combined organic layers were dried over $\mathrm{Na}_{2} \mathrm{SO}_{4}$ and the solvent evaporated in vacuo. The obtained product was recrystallized from $\mathrm{Et}_{2} \mathrm{O}$ and then dried over $\mathrm{P}_{2} \mathrm{O}_{5}$ at $90{ }^{\circ} \mathrm{C}$ under vacuum.

4-Anilinophenanthroline. Off-white solid (90\% yield). ${ }^{1} \mathrm{H} \mathrm{NMR}\left(300 \mathrm{MHz}, \mathrm{CDCl}_{3}, 300 \mathrm{~K}\right): \delta=9.18\left(\mathrm{dd},{ }^{3} J_{\mathrm{H}, \mathrm{H}}=\right.$ $\left.4.3 \mathrm{~Hz},{ }^{4} J_{\mathrm{H}, \mathrm{H}}=1.7 \mathrm{~Hz}, 1 \mathrm{H}, \mathrm{H} 9\right), 8.83\left(\mathrm{~d},{ }^{3} J_{\mathrm{H}, \mathrm{H}}=5.4 \mathrm{~Hz}, 1 \mathrm{H}, \mathrm{H} 2\right), 8.24\left(\mathrm{dd},{ }^{3} J_{\mathrm{H}, \mathrm{H}}=8.1 \mathrm{~Hz},{ }^{4} J_{\mathrm{H}, \mathrm{H}}=1.7 \mathrm{~Hz}, 1 \mathrm{H}, \mathrm{H} 7\right)$, $7.99\left(\mathrm{~d},{ }^{3} J_{\mathrm{H}, \mathrm{H}}=9.1 \mathrm{~Hz}, 1 \mathrm{H}, \mathrm{H} 5\right), 7.77\left(\mathrm{~d},{ }^{3} J_{\mathrm{H}, \mathrm{H}}=9.1 \mathrm{~Hz}, 1 \mathrm{H}, \mathrm{H} 6\right), 7.62\left(\mathrm{dd},{ }^{3} J_{\mathrm{H}, \mathrm{H}}=8.1 \mathrm{~Hz},{ }^{3} J_{\mathrm{H}, \mathrm{H}}=4.3 \mathrm{~Hz}, 1 \mathrm{H}, \mathrm{H} 8\right)$, $7.49-7.39\left(\mathrm{~m},{ }^{3} J_{\mathrm{H}, \mathrm{H}}=7.3 \mathrm{~Hz}, 2 \mathrm{H}, \mathrm{H} 3^{\prime}\right.$ e H5'), $7.37-7.29$ (m, ${ }^{3} J_{\mathrm{H}, \mathrm{H}}=7.3 \mathrm{~Hz}, 2 \mathrm{H}, \mathrm{H} 2$ ' e H6'), $7.24\left(\mathrm{~d},{ }^{3} J_{\mathrm{H}, \mathrm{H}}=5.4\right.$ $\mathrm{Hz}, 1 \mathrm{H}, \mathrm{H} 3)$, overlapped with $7.23-7.17\left(\mathrm{~m},{ }^{3} J_{\mathrm{H}, \mathrm{H}}=7.3 \mathrm{~Hz}, 1 \mathrm{H}, \mathrm{H} 4{ }^{\prime}\right) \mathrm{ppm}$. The $\mathrm{N} H$ signal was not detected. ${ }^{13} \mathrm{C}$ NMR (75 MHz, $\mathrm{CDCl}_{3}, 300 \mathrm{~K}$ ): $\delta$ = 150.6 (C9 e C2), 148.0 (C10b), 147.2 (C4), 146.6 (C10a), 140.2 (C1'), 135.9 (C7), 129.9 (C3' e C5'), 128.5 (C6a), 125.1 (C6), 124.8 (C4'), 123.1 (C8), 122.5 (C2' e C6'), 118.9 (C4a), 118.8 (C5), 105.8 (C3) ppm. Anal. Calcd. for $\mathrm{C}_{18} \mathrm{H}_{13} \mathrm{~N}_{3}$ : C, 79.68; H, 4.83; N, 15.49 Found: C, 79.29; H, 4.90; N.15.27

4-Piperidylphenanthroline. Pale yellow solid. (65\% yield). ${ }^{1} \mathrm{H}$ NMR ( $300 \mathrm{MHz}, \mathrm{CDCl}_{3}, 300 \mathrm{~K}$ ): $\delta=9.14$ (dd, $\left.{ }^{3} J_{\mathrm{H}, \mathrm{H}}=4.3 \mathrm{~Hz},{ }^{4} J_{\mathrm{H}, \mathrm{H}}=1.8 \mathrm{~Hz}, 1 \mathrm{H}, \mathrm{H} 9\right), 8.96\left(\mathrm{~d},{ }^{3} J_{\mathrm{H}, \mathrm{H}}=5.1 \mathrm{~Hz}, 1 \mathrm{H}, \mathrm{H} 2\right), 8.19\left(\mathrm{dd},{ }^{3} J_{\mathrm{H}, \mathrm{H}}=8.1 \mathrm{~Hz},{ }^{4} J_{\mathrm{H}, \mathrm{H}}=1.8 \mathrm{~Hz}\right.$, $1 \mathrm{H}, \mathrm{H} 7), 8.01\left(\mathrm{~d},{ }^{3} J_{\mathrm{H}, \mathrm{H}}=9.1 \mathrm{~Hz}, 1 \mathrm{H}, \mathrm{H} 5\right), 7.70\left(\mathrm{~d},{ }^{3} J_{\mathrm{H}, \mathrm{H}}=9.1 \mathrm{~Hz}, 1 \mathrm{H}, \mathrm{H} 6\right), 7.57\left(\mathrm{dd},{ }^{3} J_{\mathrm{H}, \mathrm{H}}=8.1 \mathrm{~Hz},{ }^{3} J_{\mathrm{H}, \mathrm{H}}=4.3 \mathrm{~Hz}\right.$, $1 \mathrm{H}, \mathrm{H} 8), 7.07\left(\mathrm{~d},{ }^{3} J_{\mathrm{H}, \mathrm{H}}=5.1 \mathrm{~Hz}, 1 \mathrm{H}, \mathrm{H} 3\right), 3.46-3.02\left(\mathrm{~m},{ }^{3} J_{\mathrm{H}, \mathrm{H}}=5.3 \mathrm{~Hz}, \mathrm{H} 2\right.$ ' and H6' piperidine, $\left.4 \mathrm{H}\right), 2.04-1.78$ (m, H3' and H5' piperidine, $4 \mathrm{H}), 1.75-1.63$ ( $\mathrm{m}, \mathrm{H} 4$ ' piperidine, $2 \mathrm{H}) \mathrm{ppm} .{ }^{13} \mathrm{C}$ NMR $\left(75 \mathrm{MHz}, \mathrm{CDCl}_{3}, 300 \mathrm{~K}\right): \delta=$ $158.3(C), 150.8$ (C9), 150.1 (C2), 147.7 (C), 147.0 (C), 135.8 (C7), 128.4 (C), 124.6 (C6), 123.6 (C), 122.8 (C8 and C5), 111.4 (C3), 53.9 (C2' and $\mathrm{C}^{\prime}$ ', piperidine), 26.3 (C3' and $\mathrm{C}^{\prime}$ ', piperidine), 24.5 (C4' piperidine) ppm. Anal. Calcd. for $\mathrm{C}_{17} \mathrm{H}_{17} \mathrm{~N}_{3}$ : C, 77.54; H, 6.51; N, 15.96 Found: C, 77.19; H, 6.52; N15.78.

3,4-Dimethylphenanthroline. In a two neck round bottom flask, 8-aminoquinoline ( $2.02 \mathrm{~g}, 14.0 \mathrm{mmol})$ and sodium 3-nitrobenzenesulfonate $(3.44 \mathrm{~g}, 15.3 \mathrm{mmol})$ were dissolved in $75 \% \mathrm{H}_{2} \mathrm{SO}_{4}(10 \mathrm{~mL}, 126 \mathrm{mmol})$, heating at $90{ }^{\circ} \mathrm{C}$ to 
allow the complete dissolution of the solids. The flask was equipped with a dropping funnel and 4-hydroxy-3methyl-2-butanone $(2.88 \mathrm{~g}, 28.2 \mathrm{mmol})$ was added over $5 \mathrm{~h}$ at $110^{\circ} \mathrm{C}$, maintaining vigorous magnetic stirring. After a further hour at $110^{\circ} \mathrm{C}$ the dark reaction mixture was allowed to cool at room temperature and slowly poured into ice water $(30 \mathrm{~mL})$. The mixture was carefully brought to basic $\mathrm{pH}$ by the addition of $28 \mathrm{w} \% \mathrm{NH}_{3}(40 \mathrm{~mL})$ and then extracted with $\mathrm{CH}_{2} \mathrm{Cl}_{2}(3 \times 40 \mathrm{~mL})$. The combined organic layers were retro-extracted with $37 \% \mathrm{HCl}(3 \times 20 \mathrm{~mL})$. The acidic solution was basified with concentrated $\mathrm{NaOH}$ solution and extracted with $\mathrm{CH}_{2} \mathrm{Cl}_{2}(3 \times 100 \mathrm{~mL})$. The organic layers were combined and the solvent evaporated in vacuo yielding $2.68 \mathrm{~g}$ of a brown solid. The product was purified by column chromatography (neutral alumina, $\mathrm{CH}_{2} \mathrm{Cl}_{2}$ ) affording $1.47 \mathrm{~g}$ of the pure product as light brown solid (7.06 mmol, $50 \%$ yield). ${ }^{1} \mathrm{H}$ NMR $\left(400 \mathrm{MHz}, \mathrm{CDCl}_{3}, 300 \mathrm{~K}\right): \delta 9.18\left(\mathrm{dd},{ }^{3} J_{\mathrm{H}, \mathrm{H}}=4.2 \mathrm{~Hz}\right.$ and ${ }^{4} J_{\mathrm{H}, \mathrm{H}}=1.7$ $\mathrm{Hz}, 1 \mathrm{H}, \mathrm{H} 9), 8.99(\mathrm{~s}, 1 \mathrm{H}, \mathrm{H} 2), 8.23\left(\mathrm{dd},{ }^{3} J_{\mathrm{H}, \mathrm{H}}=8.0 \mathrm{~Hz}\right.$ and $\left.{ }^{4} J_{\mathrm{H}, \mathrm{H}}=1.5 \mathrm{~Hz}, 1 \mathrm{H}, \mathrm{H} 7\right), 8.05\left(\mathrm{~d},{ }^{3} J_{\mathrm{H}, \mathrm{H}}=9.1 \mathrm{~Hz}, 1 \mathrm{H}\right.$, H5), $7.80\left(\mathrm{~d},{ }^{3} J_{\mathrm{H}, \mathrm{H}}=9.1 \mathrm{~Hz}, 1 \mathrm{H}, \mathrm{H} 6\right), 7.60\left(\mathrm{dd},{ }^{3} J_{\mathrm{H}, \mathrm{H}}=8.0 \mathrm{~Hz}\right.$ and $\left.{ }^{4} J_{\mathrm{H}, \mathrm{H}}=4.3 \mathrm{~Hz}, 1 \mathrm{H}, \mathrm{H} 8\right), 2.70\left(\mathrm{~s}, 3 \mathrm{H}, \mathrm{CH}_{3}\right), 2.55$ (s, 3H, $\mathrm{CH}_{3}$ ) ppm. ${ }^{13} \mathrm{C} \mathrm{NMR}\left(100 \mathrm{MHz}, \mathrm{CDCl}_{3}, 300 \mathrm{~K}\right): \delta=151.6(\mathrm{C} 2), 150.1$ (C9), $146.7(C), 144.5(C), 141.5(C)$, 135.6 (C7), 130.9 (C), 127.7 (C), 127.5 (C), 125.8 (C6), 122.5 (C5 or C8), 122.4 (C5 or C8), $17.5\left(\mathrm{CH}_{3}\right), 14.4\left(\mathrm{CH}_{3}\right)$ ppm. Anal. Calcd. for $\mathrm{C}_{14} \mathrm{H}_{12} \mathrm{~N}_{2}$ : C, 80.74; H, 5.81; N, 13.45. Found: C, 80.25; H, 5.86; N, 13.31 .

\subsection{Stoichiometric reaction of $\left[\mathrm{Pd}\left(2,9-\mathrm{Me}_{2} \mathrm{Phen}\right)\left(\mathrm{COOCH}_{3}\right)_{2}\right]$ and $p$-toluidine}

The synthesis was performed by a modification of the reaction previously reported by our group. [33]

$\left[\mathrm{Pd}\left(2,9-\mathrm{Me}_{2} \mathrm{Phen}\right)\left(\mathrm{COOCH}_{3}\right)_{2}\right]\left(9.9 \mathrm{mg}, 2.29 \times 10^{-2} \mathrm{mmol}\right)$ and $64.0 \mathrm{mg}$ of $p$-toluidine were placed in an oven dried Schlenk tube under dinitrogen atmosphere. The tube was evacuated and filled with $\mathrm{CO}$ three times, after which it was placed in an ice bath and then cold $\mathrm{CDCl}_{3}(0.80 \mathrm{~mL})$, previously presaturated with $\mathrm{CO}$, was added, followed by the addition of $50 \mu \mathrm{L}$ of a $0.03 \mathrm{M}$ solution of benzoic acid. The reaction was stirred for one hour and then transferred to an oven dried gas-tight NMR tube to check the progress of the reaction. The lack of the signal related to the $-\mathrm{COOCH}_{3}$ group of the starting complex (3.72 ppm) indicates the end of the reaction. A colorless precipitate was present mixed to palladium black. The signals of 1,3-di-p-tolylurea formed as the product were not clearly detectable in the reaction media due to its low solubility and to the presence of a large excess of aniline. So the precipitate was isolated by filtration on Hirsch funnel $\left(3.3 \mathrm{mg}, 1.37 \times 10^{-2} \mathrm{mmol}\right)$ and its identity check by ${ }^{1} \mathrm{H}$ NMR. The ${ }^{1} \mathrm{H}$ NMR signals are very close to those previously reported in the literature for $p$-tolylurea: ${ }^{1} \mathrm{H}$ NMR (300 MHz, DMSO- $\left.d_{6}\right) \delta=8.68(\mathrm{bs}, 2 \mathrm{H}, \mathrm{N} H), 7.32\left(\mathrm{~d},{ }^{3} \mathrm{~J}_{\mathrm{H}, \mathrm{H}}=8.2 \mathrm{~Hz}, 4 \mathrm{H}, \mathrm{H}_{\mathrm{Ar}}\right), 7.06\left(\mathrm{~d}, J=8.1 \mathrm{~Hz}, 4 \mathrm{H}, \mathrm{H}_{\mathrm{Ar}}\right), 2.23(\mathrm{~s}$, $\left.6 \mathrm{H}, \mathrm{CH}_{3}\right)$.

\section{Acknowledgments}

We thank Andrea Pichmeo for performing some of the syntheses and the MiUR for financial support. One of us (F.F.) thanks the University of Milano for a fellowship.

\section{References}

[1] H.-W. Engels, H.-G. Pirkl, R. Albers, R.W. Albach, J. Krause, A. Hoffmann, H. Casselmann, J. Dormish, Angew. Chem. Int. Ed., 52 (2013) 9422-9441.

[2] See the American Chemistry Councyl site at http://polyurethane.americanchemistry.com/

[3] F. Ragaini, Dalton Trans., (2009) 6251-6266.

[4] F. Paul, Coord. Chem. Rev., 203 (2000) 269-323. 
[5] S. Cenini, F. Ragaini, Catalytic Reductive Carbonylation of Organic Nitro Compounds, Kluwer Academic Publishers, Dordrecht, The Netherlands, 1996.

[6] A.M. Tafesh, J. Weiguny, Chem. Rev., 96 (1996) 2035-2052.

[7] S. Ray, D. Chaturvedi, Drug Future, 29 (2004) 343-357.

[8] S. Ray, S.A. Pathak, D. Chaturvedi, Drug Future, 30 (2005) 161-180.

[9] R.L. Metcalf, Insect Control, in: Ullmann's Encyclopedia of Industrial Chemistry, Wiley-VCH Verlag GmbH \& Co. KGaA, 2000.

[10] R. Rosenthal, J.G. Zajacek, US 3919279, 1975

[11] E. Stroefer, W. Mackenroth, M. Sohn, C. Knoesche, O. Schweers, WO 2008031755 A1, 2008

[12] Y. Dai, Y. Wang, J. Yao, Q. Wang, L. Liu, W. Chu, G. Wang, Catal. Lett., 123 (2008) 307-316.

[13] A.Y. Samuilov, F.B. Balabanova, Y.D. Samuilov, A.I. Konovalov, Russ. J. Gen. Chem., 82 (2012) 11101114.

[14] E. Delebecq, J.-P. Pascault, B. Boutevin, F. Ganachaud, Chem. Rev., 113 (2012) 80-118.

[15] O. Kreye, H. Mutlu, M.A.R. Meier, Green Chem., 15 (2013) 1431-1455.

[16] E.T. Shawl, US 4162362, 1979

[17] E.T. Shawl, US 4543419, 1985

[18] J.S. Oh, E.J. Kim, US 5384424, 1995

[19] T. Li, H. Li, G. Qin, H. Liu, Y. Pei, Front. Chem. China, 5 (2010) 99-103.

[20] E. Drent, P.W.N.M. Van Leeuwen, EP 0086281 A1 (US 4474978), 1983

[21] E. Alessio, G. Mestroni, J. Mol. Catal., 26 (1984) 337-340.

[22] E. Alessio, G. Mestroni, J. Organomet. Chem., 291 (1985) 117-127.

[23] E. Drent, EP 0231045 A2, 1987

[24] A. Bontempi, E. Alessio, G. Chanos, G. Mestroni, J. Mol. Catal., 42 (1987) 67-80.

[25] S. Cenini, F. Ragaini, M. Pizzotti, F. Porta, G. Mestroni, E. Alessio, J. Mol. Catal., 64 (1991) 179-190.

[26] P. Wehman, V.E. Kaasjager, F. Hartl, P.C.J. Kamer, P.W.N.M. van Leeuwen, J. Fraanje, K. Goubitz, Organometallics, 14 (1995) 3751-3761.

[27] M. Gasperini, F. Ragaini, S. Cenini, E. Gallo, J. Mol. Catal. A: Chem., 204-205 (2003) 107-114.

[28] F. Ragaini, C. Cognolato, M. Gasperini, S. Cenini, Angew. Chem. Int. Ed., 42 (2003) 2886-2889.

[29] F. Ragaini, M. Gasperini, S. Cenini, Adv. Synth. Catal., 346 (2004) 63-71.

[30] M. Gasperini, F. Ragaini, C. Remondini, A. Caselli, S. Cenini, J. Organomet. Chem., 690 (2005) 45174529.

[31] M. Gasperini, F. Ragaini, C. Cazzaniga, S. Cenini, Adv. Synth. Catal., 347 (2005) 105-120.

[32] M. Gasperini, F. Ragaini, S. Cenini, E. Gallo, S. Fantauzzi, Appl. Organomet. Chem., 21 (2007) 782787.

[33] F. Ragaini, M. Gasperini, S. Cenini, L. Arnera, A. Caselli, P. Macchi, N. Casati, Chem. Eur. J., 15 (2009) 8064-8077.

[34] F. Ragaini, H. Larici, M. Rimoldi, A. Caselli, F. Ferretti, P. Macchi, N. Casati, Organometallics, 30 (2011) 2385-2393.

[35] T.J. Mooibroek, L. Schoon, E. Bouwman, E. Drent, Chem. Eur. J., 17 (2011) 13318-13333.

[36] T.J. Mooibroek, E. Bouwman, E. Drent, Organometallics, 31 (2012) 4142-4156.

[37] F. Ferretti, F. Ragaini, R. Lariccia, E. Gallo, S. Cenini, Organometallics, 29 (2010) 1465-1471.

[38] P. Wehman, L. Borst, P.C.J. Kamer, P.W.N.M. van Leeuwen, J. Mol. Catal. A-Chem., 112 (1996) 23-

36.

[39] B. Van de Graaf, A.J. Hoefnagel, B.M. Wepster, J. Org.Chem., 46 (1981) 653-657.

[40] C. Hansch, A. Leo, R.W. Taft, Chem. Rev., 91 (1991) 165-195.

[41] A. Hoffmann, J. Börner, U. Flörke, S. Herres-Pawlis, Inorg. Chim. Acta, 362 (2009) 1185-1193.

[42] J. Börner, U. Flörke, K. Huber, A. Döring, D. Kuckling, S. Herres-Pawlis, Chem. Eur. J., 15 (2009) 23622376.

[43] M.J. Cook, A.R. Katritzky, S. Nadji, J. Chem. Soc., Perkin Trans. 2, (1978) 1215-1222.

[44] F.H. Case, J. Am. Chem. Soc., 71 (1949) 1828-1829.

[45] W.P. Utermohlen, J. Org.Chem., 08 (1943) 544-549. 
[46] A.P. Krapcho, S. Sparapani, J. Heterocycl. Chem., 45 (2008) 1167-1170.

[47] M.A. Bailén, R. Chinchilla, D.J. Dodsworth, C. Nájera, J. Org.Chem., 64 (1999) 8936-8939.

[48] M. Yamada, Y. Tanaka, Y. Yoshimoto, S. Kuroda, I. Shimao, Bull. Chem. Soc. Jpn., 65 (1992) 10061011.

[49] R. Santi, A.M. Romano, F. Panella, C. Santini, J. Mol. Catal. A: Chem., 127 (1997) 95-99.

[50] The use of $\left[\mathrm{Pd}(\mathrm{Phen})_{2}\right]\left[\mathrm{BF}_{4}\right]_{2}$ as the catalyst means that two equivalents of the unsubstituted ligand are always present, the ideal ligand/Pd ratios are in the range 50-200, making the small amount of unsubstituted ligand negligible with respect to the much larger amount of substituted one. Ligand exchange occurs very fast at the reaction temperature.

[51] S. Ott, R. Faust, Synthesis, 2005 (2005) 3135-3139.

[52] X. Wang, Y. Chen, G. Liu, H. Lin, J. Zhang, J. Solid State Chem., 182 (2009) 2392-2401.

[53] H. Chen, W. Gao, M. Zhu, H. Gao, J. Xue, Y. Li, Chem. Commun., 46 (2010) 8389-8391.

[54] P. Wehman, P.C.J. Kamer, P.W.N.M. van Leeuwen, Chem. Commun., (1996) 217-218.

[55] E.F. Landau, E.P. Irany, J. Org.Chem., 12 (1947) 422-425.

[56] M. Rimoldi, F. Ragaini, E. Gallo, F. Ferretti, P. Macchi, N. Casati, Dalton Trans., 41 (2012) 3648-3658. 